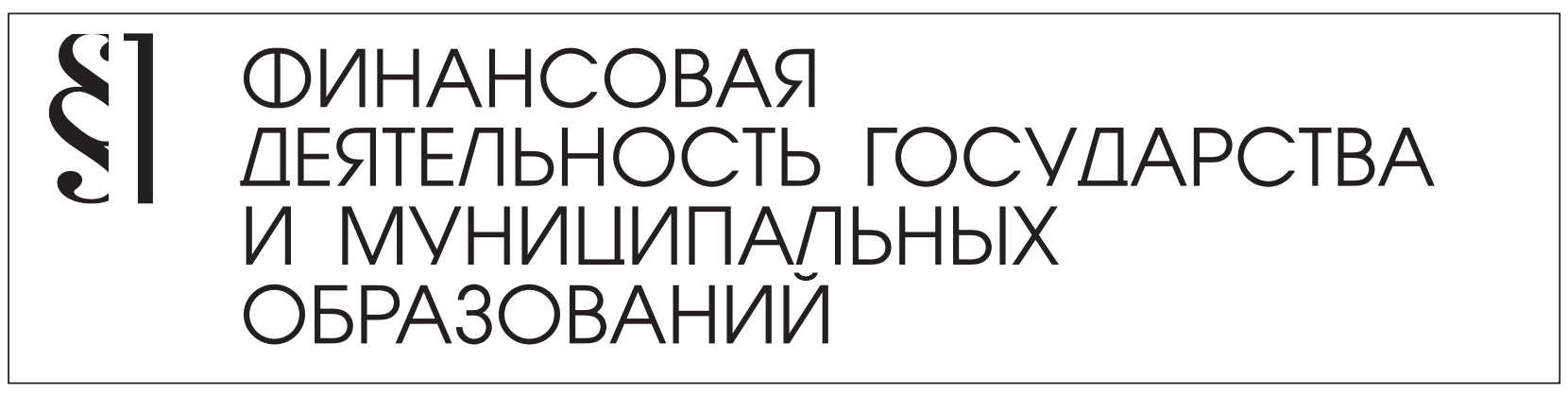

Трофимова Г.А.

\title{
ИНСТИТУТ ВРЕМЕННОЙ ФИНАНСОВОЙ АДМИНИСТРАЦИИ: ПРОБЛЕМЫ РЕАЛИЗАЦИИ
}

Аннотация. Введение временной финансовой администрации с точки зрения законодателя является действенным механизмом по восстановлению платежеспособности субъекта РФ и муниципального образования. Однако как показывает практика, данные нормы не используются. В связи с чем автор статьи предпринял попытку выяснить причину игнорирования соответствующего бюджетно-финансового и конституциионно-правового института.Для реализации поставленной задачи были рассмотрены основные элементы финансового вмешательства: понятие временной финансовой администрации, основания и цель ее введения; полномочия и условия их осуществления, срок действия и применяемые меры. Был проведен доктринальный анализ законодательных положений о временной финансовой администрации, а также исследована природа данного института, выявлены его недостатки и внесены предложения по их устранению. В частности, автором был сделан вывод о конституционно-правовом характере применения временной финансовой администрации и о нецелесообразности использования в межбюджетных отношениях штрафных санкций; а кроме того, о неприемлемости возложения ответственности за действия одного субъекта - органа или должностного лица, принимающего решения по финансовым вопросам, на другое - население субъекта РФ либо муниципального образования. С позиций материалистической диалектики в работе были использованы общенаучные и частноправовые методы познания - логический, формально-юридический, системный. Она будет полезна как в целях изучения проблем применения временной финансовой администраџии, так и для оптимизаџии имеющихся норм посредством устранения их главных недостатков. А именно: отсутствия ответственности того субъекта, кто был виновен в возникшей на уровне субъекта РФ или муниципального образования задолженности, и изменения субъекта временной финансовой администрации с государственного органа на независимого эксперта либо группь экспертов.

Ключевые слова: временная финансовая администрация, финансовая ответственность, конституциионно-правовая ответственность, бюджетная ответственность, ответственность исполнительного органа, ответственность без вины, ответственность органов государства, восстановление финансовой платежеспособности, временное осуществление полномочий, ответственность населения. 
$\mathrm{P}$ егиональные и местные органы власти находятся под контролем за своей деятельностью, в том числе финансовой. В случае состояния угрозы финансовой стабильности их полномочия могут быть на определенный срок отданы вышестоящим органам власти для исправления ситуации. Именно такой подход использован на сегодняшний день российским законодателем.

Тем не менее, к институту временной финансовой администрации на практике стараются не прибегать, однако вовсе не по тому, что финансовыми ресурсами как регионы, так и муниципальные образования обеспечены в должной мере, а руководство соответствующими территориальными образованиями более чем компетентно и самостоятельно справляется с имеющимися проблемами.

Как представляется, именно неопределенность смысла и предназначения временной финансовой администрации, условий ее проведения и является той самой причиной, из-за которой законодательные положения не выполняют отведенной для них функции. А потому видится весьма важным проанализировать имеющиеся нормы, рассмотреть позиции ученых по поводу действенности института временной финансовой администрации, чтобы сделать вывод о перспективах его дальнейшего существования.

Временное осуществление федеральными органами государственной власти, в том числе посредством введения временной финансовой администрации, отдельных полномочий органов государственной власти субъекта РФ предусмотрено ст. 26.9 Федерального закона об общих принципах организации законодательных (представительных) и исполнительных органов государственной власти Р $^{1}$. В отношении органов местного

1 См.: Федеральный закон от 6 октября 1999 года № 184-Ф3 «Об общих принципах организации законодательных (представительных) и исполнительных органов государственной власти субъектов РФ» (с последующими изм. и доп.) // СПС «КонсультантПлюс». самоуправления аналогичные правила закреплены ст. 75 Федерального закона об общих принципах организации местного самоуправления в Р $\Phi^{2}$.

Введение временной финансовой администрации, как определено в законах, предназначено для восстановления платежеспособности субъекта РФ и муниципального образования (ст. 26.9 Федерального закона об общих принципах организации законодательных (представительных) и исполнительных органов государственной власти субъектов РФ и ч. 4 ст. 75 Федерального закона об общих принципах организации местного самоуправления в РФ).

Основанием для введения временной финансовой администрации в качестве меры ответственности на уровне субъекта РФ является возникшая вследствие решений, действий или бездействия органов государственной власти субъекта РФ просроченная задолженность субъекта РФ по исполнению долговых и (или) бюджетных обязательств, определенная в порядке, установленном Бюджетным кодексом РФ, превысившая 30 процентов собственных доходов бюджета субъекта РФ в последнем отчетном году (подп. «б» п. 1 ст. 26.9 Федерального закона об общих принципах организации законодательных (представительных) и исполнительных органов государственной власти субъектов РФ); на муниципальном уровне возникшая вследствие решений, действий (бездействия) органов местного самоуправления просроченная задолженность муниципальных образований по исполнению своих долговых и (или) бюджетных обязательств, определенная в порядке, установленном Бюджетным кодексом РФ, превысившая 30 процентов собственных доходов бюджетов муниципальных образований в отчетном финансовом году, и (или)

2 См.: Федеральный закон от 6 октября 2003 года № 131-Ф3 «Об общих принципах организации местного самоуправления в РФ» (с последующими изм. и доп.) // СПС «КонсультантПлюс». 
просроченная задолженность муниципальных образований по исполнению своих бюджетных обязательств, превысившая 40 процентов бюджетных ассигнований в отчетном финансовом году, при условии выполнения бюджетных обязательств федерального бюджета и бюджетов субъектов РФ в отношении бюджетов муниципальных образований (п. 2 ч. 1 ст. 75 Федерального закона об общих принципах организации местного самоуправления в РФ) .

Под просроченной задолженностью по исполнению бюджетных обязательств субъекта РФ или муниципального образования, возникшей в результате решений, действий или бездействия органов государственной власти субъекта РФ либо органов местного самоуправления, понимаются не исполненные в установленный срок бюджетные обязательства субъекта РФ или муниципального образования, признанные в качестве таковых судом и (или) органами государственной власти субъекта РФ или органами местного самоуправления, в том числе при представлении в Министерство финансов РФ либо исполнительные органы государственной власти субъекта РФ бюджетной отчетности (п. 4 ст. 168.2 Бюджетного кодекса РФ $\left.{ }^{1}\right)$.

Субъектом, принимающим решение о возложении соответствующих полномочий на федеральные органы государственной власти, в отношении региональных органов власти выступает по ходатайству Правительства РФ Высший Арбитражный Суд РФ (п. 3 ст. 26.9 Федерального закона об общих принципах организации законодательных (представительных) и исполнительных органов государственной власти субъектов РФ); в отношении местных органов власти - по ходатайству высшего должностного лица субъекта РФ и (или) представительного

1 См.: Бюджетный кодекс РФ от 31 июля 1998 года № 145-Ф3 (с последующими изм. и доп.) // СПС «КонсультанПлюс». органа муниципального образования, главы муниципального образования - арбитражный суд субъекта РФ (ч. 4 ст. 75 Федерального закона об общих принципах организации местного самоуправления в РФ) .

Однако следует заметить, что в соответствии с Законом РФ о поправке к Конституции РФ от 5 февраля 2014 года № 2-ФКЗ «О Верховном Суде РФ и Прокуратуре РФ» ${ }^{2}$ Высший Арбитражный Суд РФ подлежит упразднению (ст. 1), а его полномочия, в том числе по введению временной финансовой администрации, после реорганизации будет осуществлять Верховный Суд РФ.

Временная финансовая администрация представляет собой федеральный орган исполнительной власти, уполномоченный Правительством РФ, или исполнительный орган государственной власти субъекта РФ, уполномоченный высшим исполнительным органом государственной власти субъекта РФ, подготавливать и осуществлять меры по восстановлению платежеспособности субъекта РФ или муниципального образования соответственно, оказывать содействие федеральным органам государственной власти или органам государственной власти субъектов РФ в осуществлении отдельных бюджетных полномочий органов государственной власти субъектов РФ или органов местного самоуправления, осуществлять и (или) контролировать осуществление отдельных бюджетных полномочий исполнительных органов государственной власти субъектов РФ либо местной администрации (ст. 168.1 Бюджетного кодекса РФ) .

Временная финансовая администрация в соответствии с Бюджетным кодексом РФ принимает меры по реструктуризации просроченной задолженности субъекта РФ, подготавливает проект закона субъекта РФ о внесении изменений и дополнений в закон субъекта РФ о бюджете субъекта РФ на текущий год,

\footnotetext{
2 См.: СПС «КонсультантПлюс».
} 
а также проект бюджета субъекта РФ на очередной год, представляет данные законопроекты в законодательный (представительный) орган государственной власти субъекта РФ, а в случаях, предусмотренных Бюджетным кодексом РФ, в Правительство РФ. Временная финансовая администрация также обеспечивает контроль за исполнением бюджета субъекта РФ и осуществляет иные полномочия, предусмотренные Бюджетным кодексом РФ (п. 3 ст. 26.9 Федерального закона об общих принципах организации законодательных (представительных) и исполнительных органов государственной власти субъектов РФ) .

Аналогичные полномочия временной финансовой администрации предусмотрены и по отношению к реструктуризации бюджета муниципального образования (ч. 4 ст. 75 Федерального закона об общих принципах организации местного самоуправления) .

Глава временной финансовой администрации наряду с руководителем финансового органа субъекта РФ или муниципального образования применяет меры принуждения, предусмотренные статьей 306.2 Бюджетного кодекса (п. 6 ст. 168.6 Бюджетного кодекса РФ).

Срок введения временной финансовой администрации не может быть больше года (п. 3 ст. 26.9 Федерального закона об общих принципах организации законодательных (представительных) и исполнительных органов государственной власти субъектов РФ и ч. 4 ст. 75 Федерального закона об общих принципах организации местного самоуправления в РФ) .

Решения федеральных органов государственной власти по поводу возложения соответствующих полномочий на федеральные органы государственной власти могут быть обжалованы в судебном порядке (п. 5 ст. 26.9 Федерального закона об общих принципах организации законодательных (представительных) и исполнительных органов государственной власти субъектов
РФ). Аналогичный порядок обжалования решений органов государственной власти субъектов РФ предусмотрен при осуществлении ими полномочий органов местного самоуправления (ч. 6 ст. 75 Федерального закона об общих принципах организации местного самоуправления в РФ).

В научной литературе указанные законодательные положения подвергнуты критике.

Так, Л.Ф. Федулова обращает внимание на то, что механизм временной финансовой администрации отличается рядом существенных недостатков: большое количество неясных или отсылочных норм, плохое ресурсное обеспечение, чрезмерная централизация финансов на федеральном уровне (решения о распределении бюджетных средств субъекта принимаются федеральным органом) ${ }^{1}$. Поэтому она видит первоочередную задачу в том, чтобы разработать нормы, регулирующие ответственность временной финансовой администрации за свои действия перед населением субъекта РФ; а законодательство о временной финансовой администрации дополнить нормой, что в случае, если ее деятельность нанесла субъекту РФ материальный ущерб, субъект РФ имеет право истребовать компенсацию в судебном порядке ${ }^{2}$.

С. В. Ковпак отмечает следующую проблему: «Определение федеральным законодателем временной финансовой администрации как органа исполнительной власти свидетельствует о том, что данный субъект власти стал частью системы органов исполнительной власти, поскольку согласно требованиям формальной логики не может существовать изолировано от нее. В то же время очевидно: в действующей системе правового регулирования положения ст. 168.1 БК

\footnotetext{
1 См.: Федулова Л. В. Конституционно-правовая ответственность высших должностных лиц субъектов Российской Федерации: автореф. дис. ... канд. юрид. наук.- М., 2007.- С. 12.

2 См.: Федулова Л. В. Указ. соч.- С. 12.
} 
РФ порождают правовую неопределенность в вопросе о статусе и месте временной финансовой администрации в системе органов исполнительной власти федерального и регионального уровней» ${ }^{1}$. С его точки зрения, должен быть создан самостоятельный орган по осуществлению полномочий временной финансовой администрации, чтобы не возлагать соответствующие полномочия на уже имеющиеся органы исполнительной власти ${ }^{2}$.

Неоднозначной является среди ученых и позиция в отношении правовой природы санкций при временной финансовой администрации. По мнению М.А. Авдеенковой и Ю.А. Дмитриева, при просроченной задолженности и нецелевом расходовании бюджетных средств будет иметь место юридическая ответственность, хотя ее нельзя назвать в чистом виде конституционно-правовой; фактически ее основанием является нарушение финансовой дисциплины, но санкции носят однозначно конституционно-правовой характер ${ }^{3}$.

О. А. Дементьева называет целый комплекс проблем:

1) отсутствие установленных на федеральном уровне мер ответственности должностных лиц и органов государственной власти субъектов РФ и должностных лиц и органов местного самоуправления муниципальных образований, в которых вводится режим временной финансовой администрации;

2) отсутствие экономических оценок целесообразности введения временной финансовой администрации;

3) отсутствие теоретической и практической проработанности вопросов ответствен-

\footnotetext{
1 Ковпак С.В. Временная финансовая администрация в системе и структуре органов исполнительной власти // Современное право.— 2009.— № 10.— С. 53.

2 См.: Ковпак С. В. Указ. соч.- С. 55.

3 См.: Конституционное право в Российской Федерации: Курс лекций: В 9 тт. Т. 1. Основы теории конституционного права / М.П. Авдеенкова, Ю.А. Дмитриев.- М.: Издательство «Весь Мир», 2005.- С. 311.
}

ности государственной власти вышестоящего уровня (прежде всего федерального) за правовую и экономическую базу, обеспечивающую сбалансированность региональных и местных бюджетов;

4) неопределенность статуса руководителя временной финансовой администрации, его ответственности за успешные или негативные результаты ее деятельности; неясность формирования корпуса кандидатов для назначения руководителем временной финансовой администрации в судебном порядке, оплаты труда руководителя и сотрудников ${ }^{4}$.

В первую очередь следует заметить, что возникшие в бюджете того или иного уровня проблемы не только могут быть, но и должны подлежать ликвидации, а для этого необходимы соответствующие меры вмешательства.

Причин возникновения задолженности, связанных с виновным поведением тех или иных органов власти, может быть несколько. Основные две - когда задолженность возникает в результате неумелого распоряжения денежными средствами и иными финансовыми ресурсами; и когда изначально бюджет соответствующего субъекта РФ или муниципального образования сформирован таким образом, что влечет невозможность исполнения возложенных финансовых обязательств.

И в первом случае вполне разумным является приведение дел в порядок посредством помощи посредника - органа или должностного лица, наделенного полномочиями по урегулированию имеющихся проблем.

Во втором случае временная финансовая администрация вводиться не должна. Более того, по заявлению органа законодательной власти субъекта РФ или же представительного органа местного самоуправления суд

\footnotetext{
4 См.: Дементьева О.А. Временная финансовая администрация как институт ответственности публичной власти // Журнал российского права._-2013.—№ 9.C. $41-42$.
} 
должен констатировать факт недостаточности средств у субъекта, в бюджете которого возникла соответствующая задолженность, и определить субъекта, ответственного за эту проблему. Ответственным субъектом может быть орган власти, не перечисливший в необходимый срок соответствующие средства в бюджет субъекта РФ или муниципального образования; орган власти, не предусмотревший должный уровень расходов на исполнение переданных или закрепленных за ответственным субъектом полномочий.

В частности, в этом направлении является актуальным предложение о возврате к идее установления минимальных государственных социальных стандартов и гарантирования соответствующей бюджетной обеспеченности ${ }^{1}$. Это будет способствовать созданию финансовой независимости, самостоятельности, a, следовательно, и реальной ответственности за исполнение полномочий теми органами нижестоящего территориального уровня, которые презюмируются в законе (в том числе в Конституции РФ) как самодостаточные субъекты.

Что касается правовой квалификации мер ответственности, то следует отметить, что введение такой меры как временное финансовое управление органами вышестоящего уровня власти вместо органов, непосредственно на это уполномоченных, влечет временное отстранение от исполнения полномочий соответствующих органов власти субъекта РФ или муниципального образования. А ограничение или лишение статусных полномочий, как правило, свидетельствует о наличии конституционно-правовых отношений между субъектами и о применении одним из них мер ответственности по отношению к другому. Однако если речь идет о взаимодействии органов исполнительной власти (то есть

1 См., в частности: Медушевский А.Н. Конституционная модернизация России: стратегия, направления, методы // Закон. - 2013. - № 12.— С. 50. субъектов, отстраняемых от финансового управления, и субъектов, осуществляющих это финансовое управление), то отношения между ними в силу подчиненности имеют административно-правовой характер.

Введение временной финансовой администрации, предполагающей вмешательство одних органов власти в систему управления других, и не прямой, а опосредованный способ применения санкции, через систему особых органов, с правом судебного обжалования, свидетельствует о конституционноправовом (а не административно-правовом) механизме временной финансовой администрации.

Преимущественно финансовый (хозяйственно-правовой) характер проводимых временной финансовой администрацией действий, направленных на восстановление платежеспособности соответствующего субъекта РФ либо муниципального образования, указывает на необходимость привлечения к осуществлению соответствующих мер не органы государства, а независимых экспертов.

В качестве посредника по налаживанию финансовых вопросов должен быть определен арбитражный управляющий — лицо, не связанное с органами власти. Порядок назначения и отбора арбитражных управляющих для осуществления функций по налаживанию платежеспособности юридических лиц уже давно установлен ${ }^{2}$, а потому может быть использован арбитражными судами и в случае просроченной задолженности субъекта РФ или муниципального образования. Однако при введении временной финансовой администрации наряду с арбитражным управляющим должна быть назначена группа из депутатов законодательного органа субъекта

2 См.: ст. 20 Федерального закона от 26 октября 2002 года № 127-Ф3 «О несостоятельности (банкротстве)» (с последующими изм. и доп.) // СПС «КонсультантПлюс». 
РФ или же представительного органа муниципального образования по проверке правомерности действий исполнительного органа власти и его должностных лиц, осуществлявших принятие решений по исполнению финансовых обязательств до реанимации финансового положения субъекта РФ или муниципального образования.

Хотелось бы отметить тот факт, что анализ норм Бюджетного кодекса РФ в части наличия бюджетного правонарушения и мер принуждения, принимаемых в связи с этим правонарушением (ст. ст. 168.6, 306.1, 306.2, 306.4-306.8), а как выше было указано, глава временной финансовой администрации может применять меры принуждения, приводит к выводу о том, что за действия органов государственной власти и местного самоуправления, осуществляющих распоряжение финансовыми средствами, субъектом ответственности признается субъект РФ или муниципальное образование, так как имеющиеся меры ответственности влекут списание бюджетных средств. То есть, по сути, субъектом ответственности является население соответствующих территорий. При этом нарушается один из принципов ответственности - ответственности за свою вину.

Кроме того, ответственность носит не компенсационный, а штрафной характер (в частности, установлено пени за просрочку обязательств - ст. 306.2 и другие статьи БК РФ), предполагающий не восстановление нарушенного положения субъектов бюджетных отношений, а их наказание. Какую функцию здесь оно выполняет, если относится не к субъекту правонарушения, а субъект ответственности фактически лишен возможности контролировать действия субъектов, принимающих решения в финансовой сфере? И может ли вообще наказание как вариант ответственности быть применим к субъекту РФ или муниципальному образованию? Это не физические или юридические лица, на деятельность которых мо- жет возыметь воздействие штраф или иное наказание, это и не субъекты коммерческой деятельности, чтобы их ответственность носила штрафной имущественный характер.

Бесспорный вариант списания денежных средств проверяющим финансовым органом (ст. ст. 306.2-306.8 БК РФ), а не судом в случае установления бюджетного правонарушения также вызывает сомнение в объективности принимаемого решения и указывает на жесткий административный характер отношений между органами управления разных территориальных уровней, нейтрализуя как самостоятельность субъектов РФ, так и муниципальных образований в финансовой сфере.

Необходимо признать, что ответственность в бюджетных отношениях, в том числе благодаря действиям временной финансовой администрации или главы этого органа, может иметь лишь восстановительный, компенсационный характер. Причем в результате проверки причин возникшей неплатежеспособности субъекта РФ или муниципального образования должны быть установлены субъекты, ответственные за возникшую ситуацию, а заявления с требованием о привлечении их к административной или уголовной ответственности направлены в органы предварительного следствия или в суд.

Было бы также справедливым после установления виновных в финансовой недееспособности субъекта РФ или муниципального образования, а это могут быть как коллективные образования (например, высший исполнительный орган субъекта РФ), так и конкретные должностные лица, возложить на них обязанность по возмещению причиненного незаконными или необоснованными действиями вреда бюджету субъекта РФ или муниципального образования, в том числе посредством уплаты пени и применения иных штрафных санкций.

Решение же о применении мер принуждения к субъектам бюджетных отношений должно основываться на вступившем в законную силу судебном акте. 


\section{Библиография}

1. Дементьева О.А. Временная финансовая администрация как институт ответственности публичной власти // Журнал российского права._2013.—№ 9.

2. Ковпак С.В. Временная финансовая администрация в системе и структуре органов исполнительной власти // Современное право.—2009.—№ 10.

3. Конституционное право в Российской Федерации: Курс лекций: В 9 тт. Т. 1. Основы теории конституционного права / М.П. Авдеенкова, Ю. А. Дмитриев.- М.: Издательство «Весь Мир», 2005.

4. Медушевский А.Н. Конституционная модернизация России: стратегия, направления, методы // Закон.-2013.—№ 12.

5. Федулова Л.В. Конституционно-правовая ответственность высших должностных лиц субъектов Российской Федерации: автореф. дис. ... канд. юрид. наук.- М., 2007.

6. Владимирова Т. В. Проблема устойчивости порядка как угроза безопасности // NB: Национальная безопасность. - 2013._- 2. - C. 67-87. DOI: 10.7256/2306-0417.2013.2.590. URL: http://www.e-notabene.ru/nb/article_590.html

\section{References (transliterated)}

1. Dement'eva O.A. Vremennaya finansovaya administratsiya kak institut otvetstvennosti publichnoi vlasti // Zhurnal rossiiskogo prava.-2013.—№ 9.

2. Kovpak S. V. Vremennaya finansovaya administratsiya $v$ sisteme i strukture organov ispolnitel'noi vlasti // Sovremennoe pravo. - 2009.—№ 10.

3. Konstitutsionnoe pravo v Rossiiskoi Federatsii: Kurs lektsii: V 9 tt. T. 1. Osnovy teorii konstitutsionnogo prava / M. P. Avdeenkova, Yu. A. Dmitriev.—M.: Izdatel'stvo «Ves' Mir», 2005.

4. Medushevskii A. N. Konstitutsionnaya modernizatsiya Rossii: strategiya, napravleniya, metody // Zakon.-2013.—№ 12.

5. Fedulova L. V. Konstitutsionno-pravovaya otvetstvennost» vysshikh dolzhnostnykh lits sub"ektov Rossiiskoi Federatsii: avtoref. dis. ... kand. yurid. nauk. - M., 2007.

6. Vladimirova T. V. Problema ustoichivosti poryadka kak ugroza bezopasnosti // NB: Natsional'naya bezopasnost».— 2013. - 2. — C. 67-87. DOI: 10.7256/2306-0417.2013.2.590. URL: http:// www.e-notabene.ru/nb/article 590.html 